\title{
PROPOSIÇÃO DE SISTEMA DE CAPTAÇÃO, ARMAZENAMENTO E APROVEITAMENTO DE ÁGUAS PLUVIAIS PARA FINS NÃO POTÁVEIS EM INSTITUIÇÃO DE ENSINO
}

Thuany Renata da Silva ${ }^{1}$, Márcia Shoji ${ }^{2}$, Edneia Aparecida de Souza Paccola ${ }^{3}$, Natália Ueda Yamaguchi ${ }^{3}$

${ }^{1}$ Graduanda do curso de Engenharia Civil do Centro Universitário de Maringá, Unicesumar - Maringá.

${ }^{2}$ Mestranda em Tecnologias Limpas no Centro Universitário de Maringá,

UniCesumar, Maringá, PR, Brasil.

${ }^{3} \operatorname{Prof}^{\mathrm{a}} \mathrm{Dr}^{\mathrm{a}}$ do Programa de Mestrado em Tecnologias Limpas do Centro Universitário de Maringá, Unicesumar - Maringá, Pesquisadora do Instituto Cesumar de Ciência,

Tecnologia e Inovação - ICETI. (natalia.yamaguchi@unicesumar.edu.br)

Recebido em: 06/04/2019 - Aprovado em: 10/06/2019 - Publicado em: 30/06/2019

DOI: 10.18677/EnciBio_2019A186

\begin{abstract}
RESUMO
Os sistemas de captação da água pluvial são tecnologias que têm ganhando espaço nos dias atuais, pois além de buscar o desenvolvimento sustentável, podem ainda trazer contribuição econômica. O armazenamento da água pluvial pode ter várias finalidades tanto potáveis como não potáveis. O estado do Paraná tem uma alta intensidade pluviométrica, e essa condição torna favorável o seu reuso. O objetivo desta pesquisa foi estudar uma alternativa sustentável e economicamente viável para poupar o uso da água do poço tubular para fins não potáveis em um prédio de uma instituição de ensino com um projeto de sistema de aproveitamento de água pluvial. A metodologia adotada verificou a frequência do uso de água na limpeza e jardinagem do local estudado, o dimensionamento do reservatório e a estimativa de custo. Concluiu-se que $65 \mathrm{~m}^{3}$ necessários para o armazenamento de águas pluvial sendo o suficiente para suprir os $85 \mathrm{~m}^{3}$ requeridos para usos não potáveis no prédio estudado, com um investimento estimado de $R \$ 38$ mil para a implantação do sistema. O sistema apresentou-se viável, pois a proposta visa à preservação do meio ambiente, visto a possível modificação do aquífero, já que aproximadamente $10 \%$ são utilizados para fins não potáveis. Dessa forma a água excedente do poço poderia ser utilizada conforme a necessidade do crescimento gradativo de alunos para fins potáveis.
\end{abstract}

PALAVRAS-CHAVE: Água da chuva. Captação pluvial. Sustentabilidade. 


\title{
PROPOSAL FOR A SYSTEM FOR THE HARVESTING, STORAGE AND RECLAMATION OF RAIN WATER FOR NON-POTABLE PURPOSES IN AN EDUCATIONAL INSTITUTION
}

\begin{abstract}
Rainwater harvesting systems are technologies that have been gaining ground nowadays, because, pursuing sustainable development, it can also bring an economic contribution. Rainwater storage can have numerous purposes, both potable and non-potable. The state of Paraná has high rainfall intensity, and this condition favors its reuse. The objective of this research was to study a sustainable and economically viable alternative to save the use of tubular well water for nonpotable purposes in a building of an educational institution with rainwater harvesting system project. The adopted methodology verified the frequency of water use in cleaning and gardening of the studied site, the design of the reservoir and the estimated cost. It was concluded that $65 \mathrm{~m}^{3}$ needed for storing rainwater sufficient to supply the $85 \mathrm{~m}^{3}$ required for non-potable uses in the studied building, with an estimated investment of $R \$ 38,000$ for the implementation of the system. The system was feasible, since the proposal aims the preservation of the environment, considering the possible modification of the aquifer, since approximately $10 \%$ are used for non-potable purposes. In this way, the surplus water from the tubular well could be used as the need for gradual growth of students for drinking purposes.
\end{abstract}

KEYWORDS: Rainwater. Rain collection. Sustainability.

\section{INTRODUÇÃO}

As discussões sobre os impactos ambientais e a carência de recursos naturais crescem gradativamente. Tecnologias voltadas para o desenvolvimento sustentável, deixaram de ser voltadas apenas para grandiosas categorias e ganharam atenção nos meios triviais como, por exemplo: comércio, residências, escolas, universidades e etc. (TORRES FILHO; TEIXEIRA, 2014).

Inúmeras questões importantes podem ser tratadas sobre tecnologias voltadas ao desenvolvimento sustentável podendo contribuir imensamente para melhorar a qualidade de vida das populações urbanas e rurais brasileiras (GOMES et al., 2014).

A ONU (Organização das Nações Unidas) vem executando, desde 2015, um plano conhecido como, "Transformando nosso mundo: A Agenda 2030 para o Desenvolvimento Sustentável", tendo 17 objetivos. Sendo um dos seus princípios proteger o planeta da degradação, sobretudo por meio do consumo e da produção sustentável, da gestão sustentável dos seus recursos naturais e tomar medidas urgentes à mudança climática, para que ele possa suportar as necessidades das gerações presentes e futuras (ONU, 2015).

A água é um recurso substancial para a vida na Terra, porém sua escassez tornou-se um problema global resultado do consumo cada vez maior dos recursos hídricos, mas acima de tudo, da falta de políticas públicas que estimulem o uso sustentável da água. A necessidade desse recurso natural é indiscutível, sendo extremamente necessário para a manutenção da vida no planeta (MANTOVANI et al., 2012).

A utilização de tecnologias que visam o uso racional de água está cada vez mais presente, e a reutilização da água através dos sistemas de captação da água 
da chuva surge como uma alternativa para amenizar as consequências do crescente consumo dos mananciais, tanto para fins potáveis como não potáveis e assim evitar um cenário de escassez de água (LIMA et al., 2017).

A água da chuva para fins não potáveis pode ser utilizada para inúmeros destinos, que vão desde descargas de bacias sanitárias, jardinagem, lavagem de pisos, calçadas e automóveis. Tantas outras atividades que podem ser feitas sem necessitar de água potável, pois usar água potável, com flúor e cloro, para tais finalidades é desperdício (SOUSA; AMORIM, 2016).

O reuso e a captação são formas importantes de gerenciamento de recursos naturais, pois são maneiras de preservar o meio ambiente com diversas vantagens ambientais, que vão desde a economia dos recursos naturais até a preservação da fauna e o bem estar da comunidade. A redução no consumo de água de distribuição para fins não potáveis acarreta a redução de custos e também do consumo das águas provenientes de fontes finitas, o que auxilia na proteção dessas fontes naturais. Com relação à viabilidade econômica estima-se uma economia de cerca de $30 \%$ dos gastos com águas potáveis (TOMAZ, 2005).

Apesar da cidade de Maringá-PR ser considerada uma cidade ecológica pela mídia, o município também sofreu as consequências do ritmo acelerado de povoamento e urbanização, que trouxe consigo sérios problemas ambientais, gerando a degradação dos recursos hídricos entre outros (BOVO; AMORIM, 2009). A captação para atender a demanda cada vez mais crescente de água na cidade de Maringá não se equivaleu apenas do Rio Pirapó, sendo necessária também a perfuração de poços semi artesianos (VENRAMEL; KOHLER, 2002).

Em pesquisa realizada em 2002, notou-se que a água de poços comuns, que era encontrada em profundidade entre 15 a 20 metros no centro de Maringá, passou a ser encontrada a 25 metros, representando uma migração do aquífero (VENRAMEL; KOHLER, 2002). Silva e Gastmans (2016) fizeram uma avaliação preliminar do rebaixamento de níveis do lençol freático na região central no munícipio de Maringá. Em consequência da atual fase de industrialização da cidade, a avaliação constatou a retirada intensiva da água, resultando na necessidade de poços cada vez mais profundos. Na prática a profundidade dos poços já está chegando à casa dos 150 metros.

Venramel e Kohler (2002) relatam também que, a degradação do rio Pirapó, o aumento dos poços tubulares, o rebaixamento de lençol freático, bem como a contaminação das águas subterrâneas são fatores que atuam como um alerta para que medidas sejam tomadas no sentido de que a sociedade se envolva num trabalho consciente de preservação e não desperdício de água.

Diante do exposto, o presente estudo propôs a implantação de um sistema de captação por gravidade, armazenamento e aproveitamento de águas pluviais para fins não potáveis em um prédio de uma instituição de ensino, que é abastecido por poços tubulares, visando o desenvolvimento sustentável, o uso racional de recursos hídricos subterrâneos, e a diminuição dos impactos ambientais em projetos de engenharia, de modo a estimular a consciência ambiental para que esta se torne habitual para as futuras gerações. 


\section{MATERIAL E MÉTODOS}

\section{Área de estudo}

O trabalho foi desenvolvido em um prédio de uma instituição de ensino na cidade de Maringá, Paraná. Este prédio consta cerca de 1870 alunos, constitui de aproximadamente $12262 \mathrm{~m}^{2}$ e contém: salas de aula, laboratórios de informática, coordenação dos cursos, salas de mestrado, secretarias, banheiros, áreas de circulação, cantina, área de gastronomia, dormitórios, e sua área externa com calçadas, estacionamentos e jardins.

\section{Estimativa do consumo de água para fins não potáveis}

A estimativa do consumo de água para fins não potáveis foi realizada a partir de visitas in loco para reconhecimento da situação do prédio em estudo, obtenção da planta, entrevistas com funcionários para obter a frequência de uso de água na limpeza e jardinagem do prédio em estudo.

\section{Dimensionamento do reservatório}

O dimensionamento do reservatório foi realizado de acordo com a NBR 10844 (ABNT, 1989) que trata sobre instalações prediais de águas pluviais, e com a NBR 15527 (ABNT, 2007) que aborda os requisitos para o aproveitamento de coberturas em áreas urbanas para fins não potáveis. Para o cálculo da área de contribuição o telhado foi considerado plano (Figura 1), e com base na NBR 10844 (ABNT, 1989), utilizou-se a Equação 1.

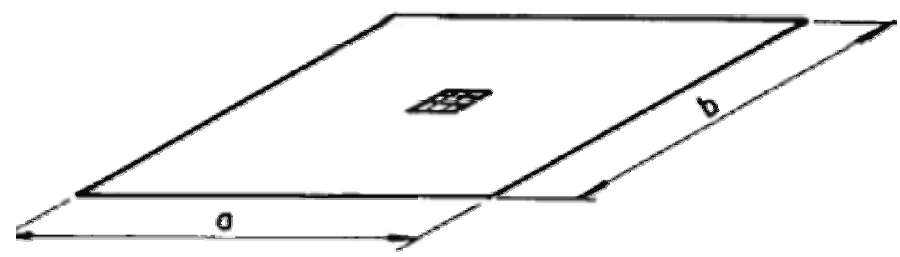

FIGURA 1. Indicação para cálculo de superfície horizontal da área de contribuição. Fonte: NBR 10844 (ABNT, 1989).

Onde:

$$
A=a \cdot b
$$

$A$ = área de contribuição $\left(\mathrm{m}^{2}\right)$;

$\mathrm{a}=$ largura da aba do telhado $(\mathrm{m})$;

$\mathrm{b}=$ comprimento lateral do telhado $(\mathrm{m})$;

De acordo com a NBR 10844 (ABNT, 1989) as superfícies horizontais de laje devem ter declividade mínima de $0,5 \%$, de modo que garanta o escoamento das águas pluviais, até os pontos de drenagem previstos. Como a inclinação da cobertura do bloco é mínima, essa inclinação foi desconsiderada por não ter grande influencia nos cálculos. O método de Azevedo Neto, NBR 15527 (ABNT,2007), foi adotado para calcular o dimensionamento do reservatório. O volume de água do reservatório foi obtido pela Equação 2:

$$
\mathrm{V}=0,042 \times \mathrm{P} \times \mathrm{A} \times \mathrm{T}
$$


Onde:

$\mathrm{P}=$ precipitação média anual $(\mathrm{mm})$;

$\mathrm{T}=$ número de meses de pouca chuva ou seca;

$A=$ área de contribuição $\left(\mathrm{m}^{2}\right)$;

$\mathrm{V}=$ volume de água aproveitável e o volume de água do reservatório (L);

Os dados pluviométricos são essenciais para o projeto, pois permitem quantificar o potencial de coleta de água e, consequentemente, auxiliam na projeção do tamanho do reservatório. Os dados pluviométricos do município de Maringá foram obtidos pelo Instituto Nacional de Meteorologia (INMET). A norma NBR 15527 (ABNT, 2007) recomenda-se que o descarte da primeira água seja de $2 \mathrm{~mm}$ da precipitação inicial por $\mathrm{m}^{2}$ de área captada, sendo então, $2 \mathrm{~L}$ de água por $\mathrm{m}^{2}$ de captação.

\section{Custo do sistema}

Com os estudos de campo agrupados com informações de projetos estruturais do prédio elaborou-se uma proposta para a localização do sistema. 0 estudo de viabilidade econômica foi realizado com a estimativa do custo do sistema e a mão de obra obtidos por orçamentos realizados por fornecedor do ramo da construção civil na cidade de Maringá-PR.

\section{RESULTADOS E DISCUSSÕES}

Os serviços de limpeza e jardinagem do prédio em estudo possui 14 funcionários para a limpeza em turnos alternados, estando quatro zeladoras de madrugada e 10 divididas em período matutino e vespertino, e cinco para a jardinagem, sendo um jardineiro e quatro auxiliares.

De acordo com as entrevistas com os funcionários da limpeza, esta atividade era dividida de duas formas: limpeza de manutenção diária, uma ou duas vezes ao dia e a limpeza completa, composta pela lavagem, geralmente uma vez ao mês, exceto os banheiros, que eram lavados todos os dias, uma vez ao dia.

É importante salientar que a quantidade de água para a limpeza e jardinagem variava de acordo com a particularidade de cada funcionário e ambiente. Desta forma, os dados foram levantados com entrevistas aos funcionários da área de limpeza de acordo com os ambientes. A estimativa de consumo de água para limpeza de manutenção diária esta apresentada na Tabela 1.

TABELA 1. Estimativa do volume de consumo de água mensal para limpeza de manutenção diária

\begin{tabular}{ccccc}
\hline AMBIENTE & QUANTIDADE FREQUÊNCIA & $\begin{array}{c}\text { TOTAL } \\
\text { L/dia }\end{array}$ & $\begin{array}{c}\text { VOLUME } \\
\text { TOTAL } \\
\text { (L/mês) }\end{array}$ \\
\hline Salas de aula e laboratórios & 57 & $2 \times /$ dia & 399 & 7980 \\
Banheiros & 17 & $2 \times /$ dia & 238 & 4760 \\
Cantina/deck & 2 & $2 \times /$ dia & 28 & 560 \\
Gastronomia & 6 & $2 x /$ dia & 42 & 840 \\
$\begin{array}{c}\text { Sala dos professores/ } \\
\text { coordenação/mestrado/xerox/ }\end{array}$ & 118 & 1x/dia & 147,5 & 2950 \\
depósito/ dormitórios & & & & \\
\hline
\end{tabular}


De acordo com as entrevistas com funcionários da limpeza, as salas de aula banheiros, cantina/deck e área gastronômica a manutenção diária era realizada com um balde de $10 \mathrm{~L}$ de volume, e dessa forma utilizou-se uma média de $7 \mathrm{~L} /$ balde de água para os cálculos. Nas salas e na área gastronômica, era utilizado um balde para duas salas, já o banheiro e a cantina/deck, um balde para cada ambiente e a água era descartada após a limpeza.

Para limpeza das salas dos professores, coordenação, salas de mestrado, xerox, depósito e dormitórios eram utilizados baldes de $5 \mathrm{~L}$ de volume, e foi utilizada uma média de 2,5 L/balde para o cálculo do volume de água, e para estes ambientes, a limpeza era feita utilizando-se um balde para duas salas, sendo a água descartada após o seu uso. Já na área de circulação, os funcionários manuseavam uma máquina de limpeza com reservatório de $120 \mathrm{~L}$, e foi calculada um média de consumo da máquina, $120 \mathrm{~L}$ de água por andar, e limpavam um andar por dia. A estimativa de consumo de água para a limpeza completa, ou seja, a lavagem, foram calculados com uma média de $2 \mathrm{~L} / \mathrm{m}^{2}$ conforme Tomaz (2005). Os resultados estão apresentados na Tabela 2.

TABELA 2. Estimativa do volume de consumo de água mensal para lavagem

\begin{tabular}{cccc}
\hline AMBIENTE & ÁREA $\left(\mathbf{m}^{2}\right)$ & FREQUÊNCIA & $\begin{array}{c}\text { VOLUME TOTAL } \\
(\mathbf{L} / \mathbf{m e ̂ s})\end{array}$ \\
\hline Salas de aula e laboratórios & 4508 & $1 \times /$ mês & 9016 \\
$\begin{array}{c}\text { Banheiros } \\
\text { Sala dos professores/ }\end{array}$ & 359 & $1 \times /$ dia & 14360 \\
$\begin{array}{c}\text { coordenação/mestrado/xerox/ } \\
\text { depósito/ dormitório } \\
\text { Cantina/deck }\end{array}$ & 3086 & $1 \times /$ mês & 6172 \\
Gastronomia & 303 & $\begin{array}{c}1 \times / \text { mês } \\
1 \times / \text { mês }\end{array}$ & 606 \\
& 492 & TOTAL $=$ & 984 \\
& & & 31138 \\
\hline
\end{tabular}

A área externa tem utilização de água não potável para jardinagem e lavagem da calçada externa. De acordo com as visitas feitas à campo e entrevistas com funcionários da jardinagem, coletou-se os seguintes dados: a jardinagem era realizada por 2 torneiras ligadas durante $1 \mathrm{~h}$ por dia e a lavagem das calçadas externas era feita por dois tanques de $3000 \mathrm{~L}$ uma vez ao mês. Para a estimativa do consumo de água para a área externa, considerou-se, pela norma NBR 5626 (ABNT, 1998), a vazão da torneira para irrigação do jardim de $0,20 \mathrm{~L} / \mathrm{s}$ ligadas apenas nos dias úteis, ou seja, 20 dias por mês. Os resultados obtidos da estimativa do volume de consumo de água mensal para área externa estão apresentados na Tabela 3. 
TABELA 3. Estimativa do volume de consumo de água mensal para área externa

\begin{tabular}{ccccc}
\hline AMBIENTE & QUANTIDADE & FREQUÊNCIA & $\begin{array}{c}\text { CONSUMO POR } \\
\text { UNIDADE }\end{array}$ & $\begin{array}{c}\text { VOLUME } \\
\text { TOTAL } \\
\text { (L/mês) }\end{array}$ \\
\hline $\begin{array}{c}\text { Jardinagem } \\
\text { Lavagem da } \\
\text { calçada } \\
\text { externa }\end{array}$ & 2 torneiras & $1 \mathrm{~h} /$ dia & $0,20 \mathrm{~L} / \mathrm{s}$ & 28800 \\
& & $1 \mathrm{x} / \mathrm{mês}$ & $3000 \mathrm{~L}$ & 6000 \\
& & & TOTAL $=$ & 34800 \\
\hline
\end{tabular}

De acordo com os resultados apresentados nas Tabelas 1, 2 e 3, têm-se uma estimativa do total do volume do consumo de água para fins não potáveis no prédio em estudo, totalizando $85.428 \mathrm{~L}$, ou seja, aproximadamente $85 \mathrm{~m}^{3}$. De posse deste resultado, a estimativa do volume total de consumo de água, deu-se então início ao dimensionamento do reservatório do sistema de captação e armazenamento de águas pluviais.

O dimensionamento do reservatório iniciou-se pelo cálculo da área de contribuição. A Figura 1 apresenta a planta de cobertura do prédio estudado, disponibilizada pela secretaria de engenharia da instituição, ilustrando as áreas destinadas para a captação das águas pluviais, tendo em vista que o telhado todo seria desnecessário e também eliminaram-se as áreas de caimento livre.

FIGURA 2. Planta de cobertura do prédio ilustrando as áreas de estudo.

A área escolhida para a captação da água foi dividas em A1 e A2. O cálculo da área de contribuição para a coleta de água foi realizado pela Equação 1 onde as duas partes foram calculadas separadamente, totalizando $724.365 \mathrm{~m}^{2}$. Os resultados estão apresentados na Tabela 4.

TABELA 4. Área de contribuição.

\begin{tabular}{lcc}
\hline Dimensões & A1 & A2 \\
\hline Comprimento $(\mathrm{m})$ & 31.200 & 7.500 \\
Largura $(\mathrm{m})$ & 18.950 & 17.750
\end{tabular}




\begin{tabular}{lcc} 
Área $\left(\mathrm{m}^{2}\right)$ & 591.240 & 133.125 \\
Área total $\left(\mathrm{m}^{2}\right)$ & 724.365 \\
\hline
\end{tabular}

A precipitação média anual $(\mathrm{P})$ é necessária para o dimensionamento do reservatório (Equação 2). Para determinação da média anual pluviométrica, a médias mensais dos últimos 5 anos foram obtidos pelo INMET e somadas, resultando então na média anual de cada ano, as médias anuais foram então somadas e divididas por cinco, resultando então na média anual dos últimos cinco anos $(\mathrm{P})$. Os resultados estão apresentados na Tabela 5.

TABELA 5. Dados pluviométricos do município de Maringá em cinco anos com a média anual de cada ano

\begin{tabular}{|c|c|c|c|c|c|c|c|c|c|c|c|c|c|}
\hline ANO & MAR & ABR & MAI & JUN & JUL & AGO & SET & OUT & NOV & DEZ & JAN & FEV & $\begin{array}{l}\text { MÉDIA } \\
\text { ANUAL } \\
(\mathrm{mm})\end{array}$ \\
\hline $\begin{array}{l}2013 / \\
2014\end{array}$ & 225 & 170 & 185 & 370 & 85 & 10 & 70 & 230 & 70 & 70 & 190 & 195 & 1870 \\
\hline $\begin{array}{l}2014 / \\
2015\end{array}$ & 390 & 165 & 125 & 140 & 130 & 50 & 150 & 60 & 150 & 240 & 240 & 210 & 2050 \\
\hline $\begin{array}{c}2015 / \\
2016\end{array}$ & 350 & 90 & 180 & 20 & 380 & 50 & 240 & 310 & 365 & 330 & 415 & 390 & 3120 \\
\hline $\begin{array}{l}2016 / \\
2017\end{array}$ & 100 & 130 & 260 & 80 & 60 & 150 & 40 & 150 & 40 & 220 & 345 & 150 & 1725 \\
\hline $\begin{array}{l}2017 / \\
2018\end{array}$ & 150 & 16 & 305 & 100 & 0 & 145 & 40 & 315 & 170 & 220 & 360 & 90 & 1911 \\
\hline & & & & \multicolumn{7}{|c|}{ Média anual dos últimos 5 anos $(P)=$} & \multicolumn{3}{|c|}{$2135,2 \mathrm{~mm}$} \\
\hline
\end{tabular}

Fonte: adaptado de INMET (2019)

O Método Azevedo Neto segundo a NBR 15527 (ABNT, 2007), considera os meses de pouca chuva ou seca, segundo a Equação 2. A Tabela 6 apresenta a média dos meses dos últimos cinco anos de dados pluviométricos obtidos do INMET.

TABELA 6. Média Pluviométrica mensal, em milímetros, dos últimos cinco anos em Maringá $(2013-2018)$

\begin{tabular}{ccccccccccccc}
\hline Mês & MAR & ABR & MAI & JUN JUL & AGO & SET & OUT & NOV & DEZ & JAN & FEV \\
\hline $\begin{array}{c}\text { Média } \\
\text { pluviométrica } \\
(\mathrm{mm})\end{array}$ & 243 & 114 & 211 & 142 & 131 & 81 & 108 & 213 & 159 & 216 & 310 & 207 \\
\hline
\end{tabular}

Fonte: adaptado de INMET (2019)

Segundo Terassi et al., (2016), os meses de julho e agosto caracterizam-se pelos meses mais secos. Comparando-os, o mês de agosto é o mês mais seco. Dessa forma, o mesmo foi usado como o único mês de seca, visto que somente este tem a média mensal dos últimos cinco anos abaixo de $100 \mathrm{~mm}$ sendo $\mathrm{T}=1$ (único mês de pouca chuva) na Equação 2.

O volume foi calculado utilizando a Equação 2, onde tem-se a precipitação média anual em cinco anos $(P)$ na Tabela 5 , a área de contribuição $(A)$ na Tabela 4 e a quantidade de mês de pouca chuva ou seca $(T=1)$ obtido pela Tabela 6 . 
Dessa forma, o volume do reservatório da cisterna (V) calculado foi de $64959,9 \mathrm{~L}$, ou seja, aproximadamente $65 \mathrm{~m}^{3}$. Conforme Martini (2014), a cisterna precisará ter capacidade suficiente de armazenamento de água para atender a demanda necessária por um período mínimo de 15 dias. Uma vez que quanto menos tempo esta água permanecer armazenada menor a necessidade de desinfecção do mesmo.

O volume estimado para fins não potáveis verificado nas Tabelas 1 a 3 , é de aproximadamente $85 \mathrm{~m}^{3}$, e o volume de armazenamento pluvial é de $65 \mathrm{~m}^{3}$, garantindo um período maior que 15 dias de armazenamento, permitindo assim que o sistema exerça a função tal qual foi destinado.

Por meio de informações obtidas pela secretaria de engenharia da instituição, sabe-se que o prédio em estudo utiliza aproximadamente $581,8 \mathrm{~m}^{3}$, oriunda do poço tubular já existe no local, deste modo, o sistema projetado supriria cerca de $15 \%$ da demanda do edifício.

Foi proposto um sistema de captação e armazenamento com a instalação de três reservatórios de $15.000 \mathrm{~L}$ cada na parte externa apoiados em uma laje de concreto armado com espessura de $15 \mathrm{~cm}$, na parte lateral do prédio onde se encontra uma pequena área entre o estacionamento da área gastronômica e o deck com pequeno fluxo de pessoas, e oito caixas d'água de $2.500 \mathrm{~L}$ agrupadas em duplas e espalhadas ao longo da superfície da laje de painel treliçado já existente. O orçamento realizado em uma empresa do ramo da construção civil em MaringáPR para o sistema proposto encontra-se apresentado na Tabela 7.

TABELA 7. Orçamento para o sistema de captação e armazenamento para reaproveitamento de águas pluviais para fins não potáveis.

\begin{tabular}{lll}
\hline PRODUTO/SERVIÇO & VALOR & SUB TOTAL \\
\hline
\end{tabular}

Kit de filtragem para água de

chuva (filtro, freio aerados 200

mm, multi sifão 200 mm, bóia mangueira $32 \mathrm{~mm}$ )

Realimentador $25 \mathrm{~mm}$

Bomba pressurizadora com pressostato

Tanque $15.000 \mathrm{~L}$

Tanque $2.500 \mathrm{~L}$

Tubos e conexões diversas

Instalação (mão-de-obra)

1

$3.562,65$

$3.562,65$

1

1

3

8

1

1
492,08

$1.026,00$

$5.258,60$

$1.208,60$

$4.938,80$

$2.400,00$

TOTAL $=$
492,08

$1.026,00$

$15.775,80$

$9.668,80$

$4.938,80$

$2.400,00$

$37.864,13$

Comparando-se ao projeto de Lima et al. (2017) que possui uma estimativa de consumo de água não potável de $66,14 \mathrm{~m}^{3}$ e um armazenamento com capacidade de $50 \mathrm{~m}^{3}$, o respectivo orçamento sucedeu-se em $R \$ 29.593,29$, logo o presente trabalho com o custo de $\mathrm{R} \$ 37.864,13$ encontra-se em um orçamento eficiente, pois traz uma proposta sustentável, utilizando a gravidade, e nota-se que quantidade de reservatórios poderiam ainda ser substituídos por um único reservatório maior, diminuindo ainda mais o orçamento. 


\section{CONCLUSÃO}

Diante dos resultados obtidos, a implantação do sistema de captação de água pluvial apresentou-se como uma alternativa viável. A preservação ambiental é uma questão de fundamental importância que se deve ter como prioridade em construções uma vez que recursos naturais estão chegando à sua exaustão, o reuso dos mesmos contribuem para o desenvolvimento sustentável. O crédito de água potável de $15 \%$ que existirá no poço tubular com a implantação do presente estudo, poderá ser utilizado futuramente conforme a necessidade crescente dos alunos. Além disso, colabora com a preservação do aqüífero que pode estar sendo modificado.

\section{REFERÊNCIAS}

ABNT - ASSOCIAÇÃO BRASILEIRA DE NORMAS TÉCNICAS. NBR 10844: Instalação predial de águas pluviais. Rio de Janeiro, 1989.

ABNT - ASSOCIAÇÃO BRASILEIRA DE NORMAS TÉCNICAS. NBR 15527: Água de chuva - Aproveitamento de coberturas em áreas urbanas para fins não potáveis - Requisitos. Rio de Janeiro, 2007.

ABNT - ASSOCIAÇÃO BRASILEIRA DE NORMAS TÉCNICAS. NBR 5626: Instalação predial de água fria. Rio de Janeiro, 1998.

BOVO, M. C.; AMORIM, M. C. C. T. Áreas verdes urbanas, a imagem, o mito e a realidade: um estudo de caso sobre a cidade de Maringá/PR/BR. Revista Formação, n. 16, v. 1, p. 60-69, 2009. Disponível em: $<$ file://Users/Natalia/Downloads/865-2429-1-PB.pdf>.

GOMES, U. A. F.; DOMÉNECH, L.; PENA, J. L.; HELLER, L.; PALMIER, L. R. A captação da água da chuva no Brasil: Novos aportes a partir de um olhar internacional. Revista Brasileira de Recursos Hídricos. v. 19, n.1, 2014. Disponível

em:<https://www.researchgate.net/profile/Leo_Heller/publication/261712164_A_Capt acao_de_Agua_de_Chuva_no_Brasil_Novos_Aportes_a_Partir_de_um_Olhar_Intern acional/links/00b7d5353d1 $\overline{d e} 32 \mathrm{f} 08000000 . p \mathrm{df}>$.

INMET. Instituto Nacional de Meteorologia. Gráficos. 2019. Disponível: $<$ http://www.inmet.gov.br/portal/index.php?r=tempo/graficos>. Acesso em: 9 mai. 2019.

LIMA, K. L. B. A.; NUNES, L. G. C. F.; SILVA, S. R. Análise de viabilidade de implantação de captação de águas pluviais em escola pública no Recife-PE. Revista Nacional de Gerenciamento de Cidades. v. 5, n. 36, 2017. Disponível em:<http://dx.doi.org/10.17271/2318847253620171630>.

Doi: $10.17271 / 2318847253620171630$

MANTOVANI, D.; CORAZZA, M.L.; FILHO, L. C.; COSTA, S. C.; SCHMIDT, C. A. P. Levantamento pluviométrico e qualidade microbiológica e físico-química da água da chuva na cidade de Maringá, Paraná. Revista Tecnológica.v 21, p. 93- 102, 2012. 
Disponível em:<http://dx.doi.org/10.4025/revtecnol.v21i1.15163.g10284>. Doi: 10.4025/revtecnol.v21i1.15163.g10284.

MARTINI, CRISTIAN. Viabilidade de implantação de cisternas para captação de água da chuva em propriedades rurais do município de Itá- SC. Monografia de especialização, $2014 . \quad$ Disponível < http://repositorio.roca.utfpr.edu.br/jspui/bitstream/1/4513/1/MD_GAMUNI_2014_2_25 .pdf>

ONU - Organização das Nações Unidas. Transformando Nosso Mundo: A Agenda 2030 para o Desenvolvimento Sustentável, 2015. Disponível em:<https://nacoesunidas.org/pos2015/agenda2030/>

SILVA, H. V.; GASTMANS, D. Uma avaliação preliminar do rebaixamento de níveis do freático na região central no município de Maringá - PR. Anais do XIX Congresso brasileiro de águas subterrâneas, 2016. Disponível em: $<$ https://aguassubterraneas.abas.org/asubterraneas/article/view/28719/18626>.

SOUZA, T. M.; AMORIM, L. M. M. F. Análise da viabilidade do aproveitamento de água pluvial para fins não potáveis de um clube recreativo, na cidade de MaringáPR. Revista UNINGÁ Review. v. 28, n.2, p. 31-39, 2016. Disponível em: < http://revista.uninga.br/index.php/uningareviews/article/view/1870/1469>.

TOMAZ, P.; Aproveitamento de Água de Chuva para Áreas Urbanas e Fins não Potáveis. 2 ed. São Paulo: Navegar Editora, 2005, 184 p.

TERASSI, P.M.B.; SILVEIRA, H.; GRAÇA, C.H. Intensidade pluviométrica diária e a erosividade na unidade hidrográfica Pirapó, Paranapanema III e IV, Estado do Paraná. Revista online - Caminhos de Geografia v.17 n.59,2016. Disponível em: < https://doi.org/10.14393/RCG175906>. Doi: 10.14393/RCG175906.

TORRES FILHO, R. J. A.; TEIXEIRA, C. A. Avaliação do potencial e dimensionamento das instalações para o aproveitamento de água de chuva para fins não-potáveis no campus Curitiba. Revista Engenharia e Construção Civil. v.1 n. 2, 2014. Disponível em:< https://periodicos.utfpr.edu.br/recc/article/view/6611/4262>.

VENDRAMEL, E.; KOHLER. V. B. A história do abastecimento de água em Maringá, Estado do Paraná. Revista Acta Scientiarum. v. 24 n.1, 2002. Disponível em: <http://dx.doi.org/10.4025/actascihumansoc.v24i0.2445>.

Doi:10.4025/actascihumansoc.v24i0.2445. 